\title{
Efficacy of Morpho-Geometrical Analysis of the Corneal Surfaces in Keratoconus Disease According to Moderate Visual Limitation
}

\author{
J.S. Velázquez-Blázquez ${ }^{1[0000-0002-1329-5093]}$, D.G. Fernández-Pacheco ${ }^{1[0000-0002-1504-8475]}$, \\ J. Alió del Barrio 2,3[0000-0003-2666-3366], J.L. Alióo ${ }^{2,3}$ and F. Cavas-Martínez ${ }^{*}$,10000-0002-8391- \\ 0688] \\ 1 Department of Graphical Expression, Technical University of Cartagena, 30202 Cartagena, \\ Spain \\ 2 Keratoconus Unit of Vissum Corporation Alicante, 03016 Alicante, Spain \\ 3 Department of Ophthalmology, Miguel Hernández University of Elche, 03202 Alicante, \\ Spain \\ *francisco.cavas@upct.es
}

\begin{abstract}
The cornea is a complex hemispheric structure, made of collagen fibres that provide it a homogenous and stable geometry. During keratoconus disease, a loss of tenacity takes place in the collagen fibres that form the corneal structure, producing an alteration of its geometry, this is, a change of its curvature, and therefore, a loss of visual quality of patients. The geometric characterization of the hemispheric structure by means of biometric parameters is a very solid technique of diagnosis, based in a virtual 3D model, which has already been validated for several degrees of severity of keratoconus pathology. In this prospective comparative study, 93 corneas ( 50 healthy subjects and 43 patients with keratoconus with moderate visual limitation) were geometrically modelled. The results obtained in this work suggest that the best predictive biometric parameters are anterior corneal surface area and posterior apex deviation, and that the strongest correlation is produced between sagittal plane apex area in minimum thickness point and sagittal plane apex area. The studied biometric parameters have shown significant differences between groups. Therefore, the analysis of the biometric parameters that register the geometric decompensation that locally appear in a corneal region, as a response to the asymmetry produced during the development of keratoconus disease with a moderate visual impairment, is a new approach that may lead to a better understanding of the disease with this degree of optical limitation.
\end{abstract}

Keywords: Computer-Aided Geometric Design (CAGD), Optical Aberrometry, Scheimpflug, 3D Modelling.

\section{Introduction}

The cornea is an avascular structure with a hemispheric shape that is part of the anterior segment of the human eye [1]. It is a highly differenced tissue with five layers which 
have different functions, being the most important the one of the first ocular refractive element, due to its properties of transparency and curvature along all the structure [2].

One of the main pathologies of the cornea is keratoconus, which is a clinical term that describes a corneal condition characterized by its progressive thinning, which causes a cone-shaped corneal protrusion [3]. This degenerative geometrical deformation leads to a decrease of cornea's optical quality.

The knowledge, from a clinical point of view, of the geometrical characteristics of the cornea is important in clinical practice [1]. There are several studies in scientific literature which have validated indexes or topographic descriptors of the cornea $[3,4]$ in order to define the cut off values that allow the discrimination between normal and keratoconus corneas. From this indexes, several keratoconus classifications have been proposed, such as a morphological classification [1], keratometric [5], of keratoconus severity [6], or Amsler-Krumeich [1]. However, none of these classifications measures the degree of severity of keratoconus depending on the visual limitation level.

In addition, computer-aided design is a widespread tool for biological structure modelling [7-9], and its later use for disease diagnosis [10,11]. Our research group have developed some new virtual geometric models of the human cornea that have been used to characterize corneal ectasia disease basing on Amsler-Krumeich classification [1214], and for other classification, named RETICS [15], which allows characterizing keratoconus' pathology considering visual performance of patients in its initial phases $[16,17]$.

This investigation work proposes a way to characterize cornea's morphogeometry in keratoconus pathology with a moderate degree of visual performance, and also to quantify the existence of correlations between the geometries of corneal surfaces for this degree of severity of the disease.

\section{Materials and Methods}

\subsection{Participants}

This observational case series study evaluated 93 corneas of 93 patients (selected at random to avoid interference) structured in two groups: a normal group (healthy corneas), which included 50 subjects presenting no ocular pathology (36.80 \pm 15.67 years); and a second group, composed of 43 patients diagnosed with moderate KC (46.67 \pm 24.99 years). The classification protocol for normal or moderate $\mathrm{KC}$ cases was run according to reported state of the art of clinical and topographic evaluations [18].

All patients were selected according to the RETICS grading. Inclusion criteria were patients diagnosed as Grade III KC eyes (moderate visual impairment, $0.4<$ CDVA $\leq$ 0.6 in decimal scale, or $6 / 15<$ CDVA $\leq 6 / 9.5$ Snellen), corneal topography revealing a localized steepening, and/or an asymmetric bowtie pattern with or without skewed radial axis. The exclusion criteria were the following: any previous ocular surgery, ocular surface inflammation, moderate to severe dry eye or other active ocular comorbidity, or use of contact lenses within the four weeks prior to the first visit.

These evaluations were made at Vissum Instituto Oftalmologico Alicante, Spain (Vissum) who were adequately informed about the clinical study and voluntarily signed 
their consent to participate. The study was ratified by the clinic's Institutional Review Board in compliance with the ethical restrictions established in the Declaration of Helsinki (Seventh revision, October 2013, Fortaleza, Brasil).

\subsection{Examination Protocol}

All subjects selected for this study were examined using Sirius System® (CSO, Florence, Italy), and following a validated protocol previously created by our research group, which has been thoroughly described in preceding studies [14,12,13], and that has proved itself successful when used for diagnosis and characterization of $\mathrm{KC}$ in asymptomatic (pre-clinical) and mild visually-impaired eyes $[17,16]$.

The final output of this protocol after its application, is a patient-specific $3 \mathrm{D}$ virtual model of the cornea, which is then analysed to find several biometric parameters (Figure 1). These biometric parameters studied herein, along with their characteristics, have been previously described in [19], and are summarized in Table 1, but are used for the first time to study KC eyes with moderate visual impairment. In this study, the Rhinoceros' surface was deformed to minimise the nominal distance between the spatial points and the surface. This deviation could be later calculated by the software, providing a mean value of the distance error for the solution surface of $5.560 \times 10^{-17} \pm 5.81 \times 10^{-17}$ $\mathrm{mm}$ (mean \pm standard deviation).

Table 1. Biometric parameters analysed in the study.

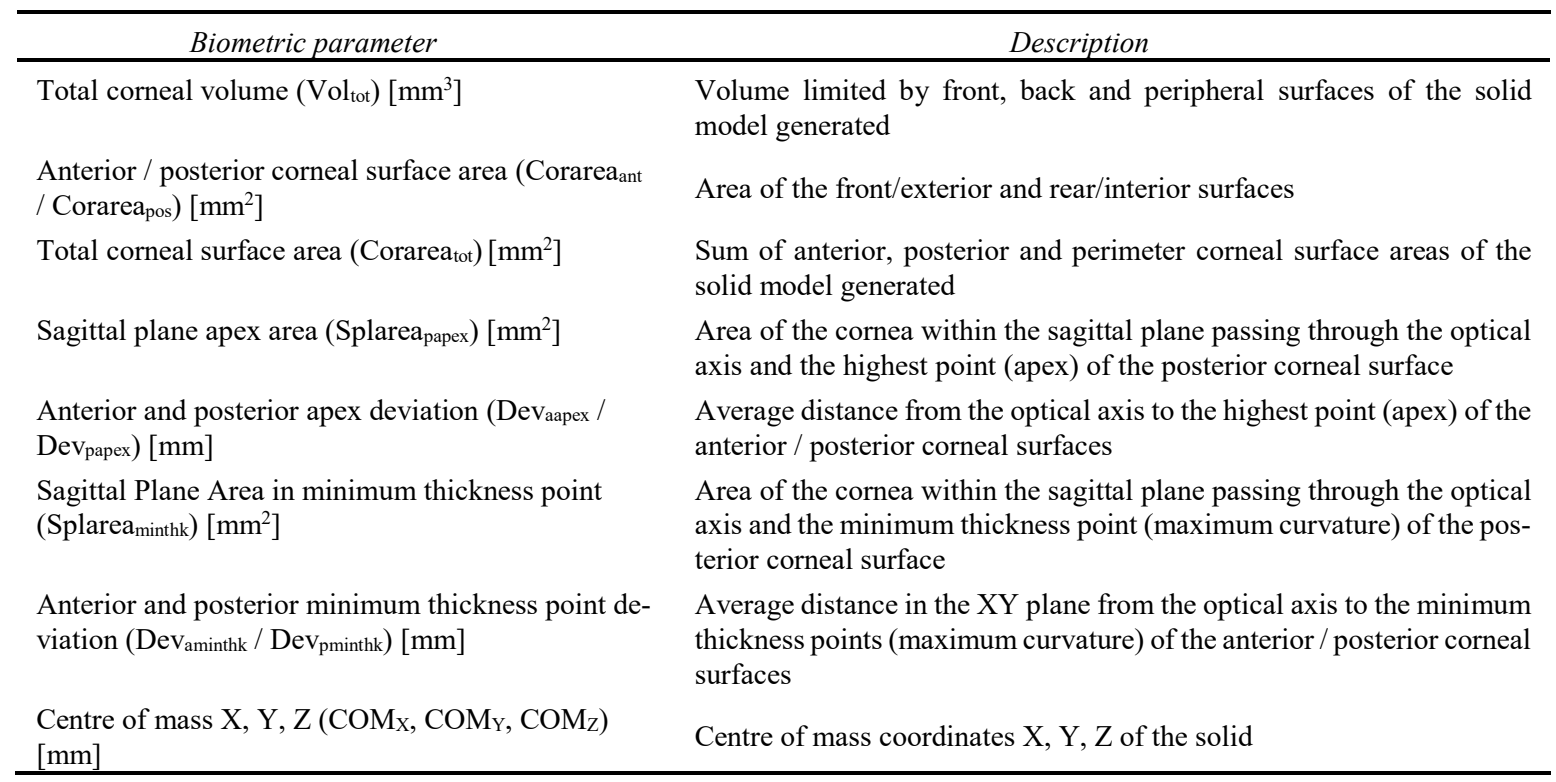




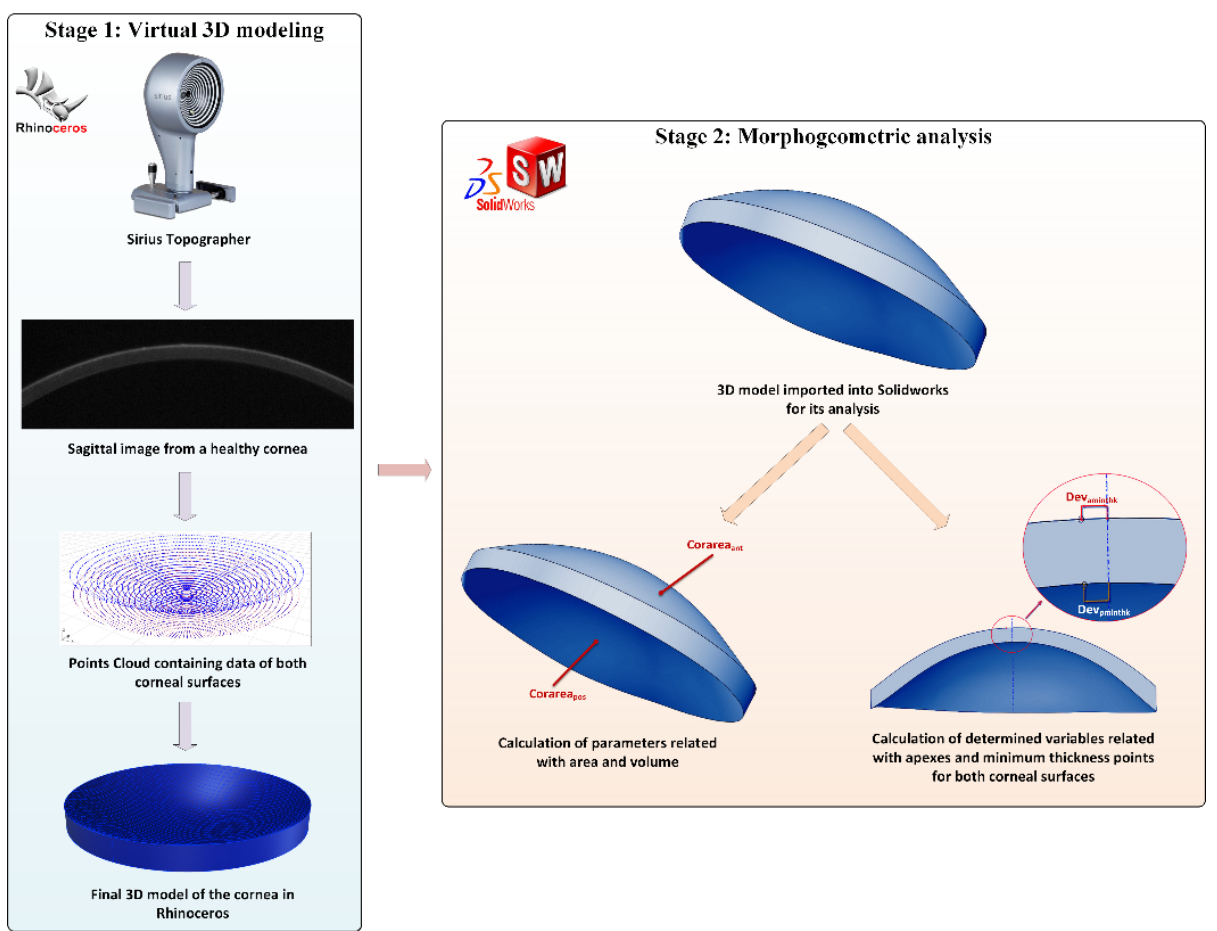

Fig. 1. Scheme of the procedure for the generation of a virtual model and later analysis of the corneal structure.

\subsection{Statistical Analysis}

Both Kolmogorov-Smirnov test and Shapiro-Wilks test were run to check data normality. According to these tests and thereafter, a Student's T-test or U-Mann Whitney Wilcoxon test were employed, when appropriate. Correlation between parameters was assessed by means of Pearson coefficients (for normally distributed data) or Spearman coefficients (not normally distributed). A significance level of 0.05 was fixed for pvalues in all statistical tests. Receiver operating characteristics (ROC) curves were used to determine which parameters could be useful in terms of characterization of diseased corneas, and optimal cut-offs were stablished using Youden's J index, basing on sensitivity and specificity values [20,21]. Graphpad Prism V 6 (GraphPad Software, La Jolla, USA) and IBM SPSS V 23.0 software (SPSS, Chicago, USA) were used to make all the analyses.

\section{$3 \quad$ Results}

Most of the modelled parameters showed statistically significant differences when comparing healthy and moderate KC corneas, as shown in Table 2 below. 
Table 2. Descriptive values and differences in the modelled biometric parameters among the normal and moderate KC groups. SD: standard deviation. P: statistical test, Z: Z-score.

\begin{tabular}{|c|c|c|c|c|c|c|c|c|c|c|}
\hline \multirow{2}{*}{$\begin{array}{c}\text { Biometric } \\
\text { Parameters }\end{array}$} & \multicolumn{4}{|c|}{ Normal Group $(n=50)$} & \multicolumn{4}{|c|}{ Moderate KC Group $(n=43)$} & \multirow[b]{2}{*}{$z$} & \multirow[b]{2}{*}{$P$} \\
\hline & Mean & $S D$ & Min & $\operatorname{Max}$ & Mean & $S D$ & Min & Max & & \\
\hline Voltot $_{\left(\mathrm{mm}^{3}\right)}$ & 25.71 & 1.53 & 23.23 & 29.07 & 23.97 & 1.52 & 21.06 & 28.74 & -5.16 & 0.000 \\
\hline Corarea $a_{a n t}\left(\mathrm{~mm}^{2}\right)$ & 43.08 & 0.14 & 42.77 & 43.33 & 43.67 & 0.47 & 42.79 & 45.09 & -7.37 & 0.000 \\
\hline Corareapos $\left(\mathrm{mm}^{2}\right)$ & 44.24 & 0.26 & 43.53 & 44.71 & 45.22 & 0.80 & 44.17 & 47.53 & -7.24 & 0.000 \\
\hline Corareatot $\left(\mathrm{mm}^{2}\right)$ & 103.87 & 1.12 & 100.73 & 105.66 & 104.91 & 1.70 & 101.91 & 109.95 & -3.47 & 0.001 \\
\hline Splarea $a_{p a p e x}\left(\mathrm{~mm}^{2}\right)$ & 4.32 & 0.26 & 3.93 & 4.87 & 3.93 & 0.29 & 3.19 & 4.83 & 6.72 & 0.000 \\
\hline Splarea ${ }_{\text {minthk }}\left(\mathrm{mm}^{2}\right)$ & 4.31 & 0.26 & 3.92 & 4.86 & 3.92 & 0.29 & 3.19 & 4.82 & 6.61 & 0.000 \\
\hline $\operatorname{Dev}_{\text {aapex }}(\mathrm{mm})$ & 0.00 & 0.00 & 0.00 & 0.01 & 0.02 & 0.00 & 0.00 & 0.07 & -7.57 & 0.000 \\
\hline $\operatorname{Dev}_{\text {papex }}(\mathrm{mm})$ & 0.07 & 0.02 & 0.04 & 0.09 & 0.21 & 0.08 & 0.03 & 0.34 & -7.37 & 0.000 \\
\hline $\operatorname{COMx}_{(\mathrm{mm})}$ & 0.04 & 0.02 & 0.01 & 0.09 & 0.02 & 0.05 & -0.15 & 0.20 & 3.39 & 0.001 \\
\hline $\mathrm{COM}_{\mathrm{Y}}(\mathrm{mm})$ & 0.03 & 0.02 & 0.00 & 0.08 & 0.00 & 0.05 & -0.14 & 0.16 & -5.14 & 0.000 \\
\hline $\mathrm{COMz}(\mathrm{mm})$ & 0.77 & 0.02 & 0.71 & 0.81 & 0.83 & 0.06 & 0.72 & 1.00 & -6.26 & 0.000 \\
\hline Devaminthk (mm) & 0.83 & 0.21 & 0.44 & 1.27 & 0.81 & 0.09 & 0.35 & 1.81 & 0.37 & 0.713 \\
\hline $\operatorname{Dev}_{\text {pminthk }}(\mathrm{mm})$ & 0.76 & 0.20 & 0.38 & 1.24 & 0.74 & 0.26 & 0.30 & 1.31 & 0.57 & 0.570 \\
\hline
\end{tabular}

\subsection{Roc Analysis}

A ROC analysis was used to ascertain the predictive value of the modelled parameters (Figure 2). Five biometric parameters showed an area under the ROC (AUROC) above 0.7 (Table 3).

Table 3. The area under the ROC results.

\begin{tabular}{lrccc}
\hline Biometric Parameters & AUROC & Sensitivity & Specificity & Cut off value \\
\hline Corarea $_{\text {ant }}$ & 0.945 & 86.0 & 96.0 & $\geq 43.2595 \mathrm{~mm}^{2}$ \\
Corarea $_{\text {pos }}$ & 0.937 & 83.7 & 96.0 & $\geq 44.6205 \mathrm{~mm}^{2}$ \\
Devaapex $_{\text {Devpapex }}$ & 0.910 & 83.7 & 94.0 & $\geq 0.0010 \mathrm{~mm}$ \\
COMz & 0.945 & 93.0 & 99.9 & $\geq 0.0965 \mathrm{~mm}$ \\
\hline
\end{tabular}




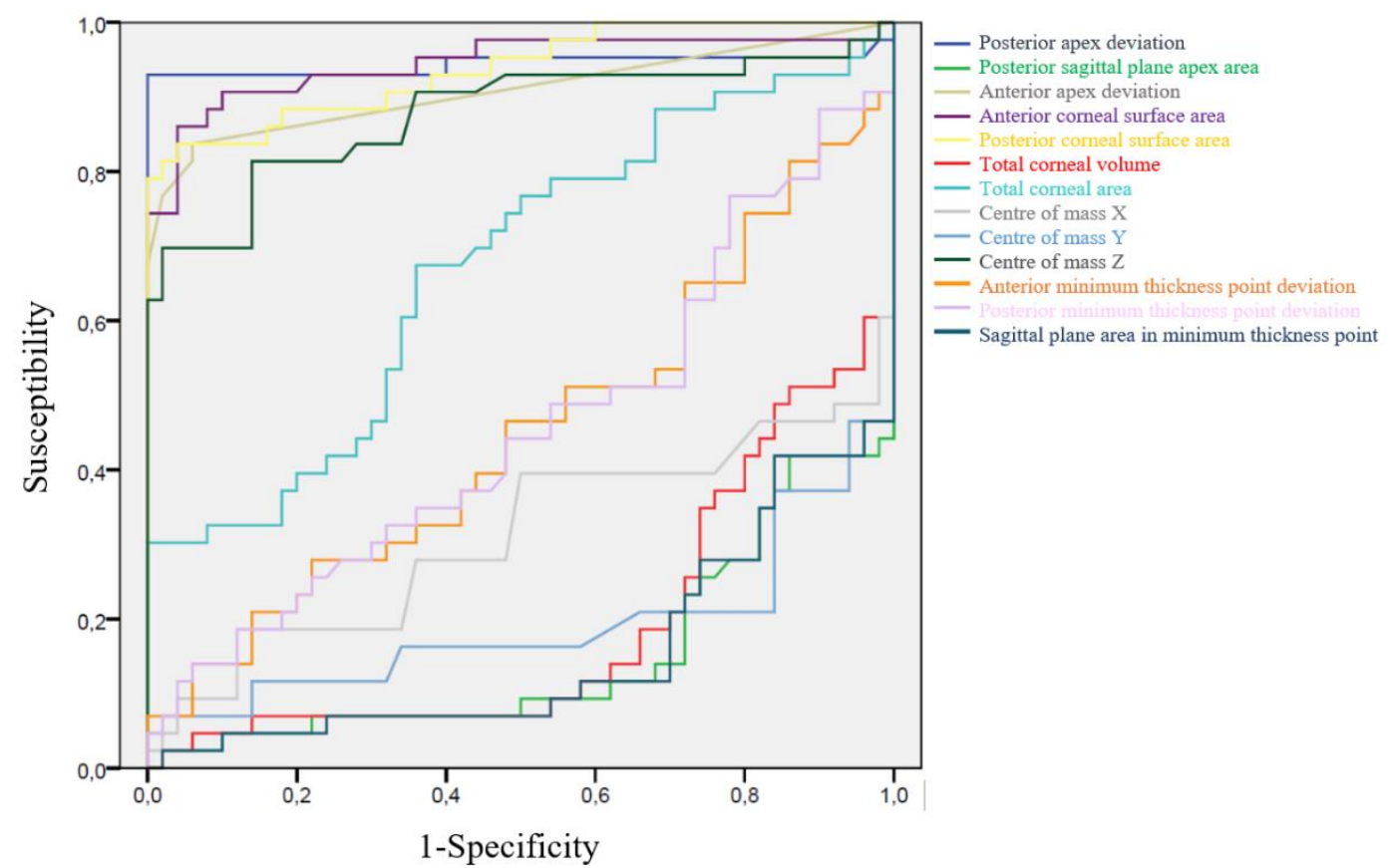

Fig. 2. Curves for modelled parameters detecting moderate KC.

Table 4 summarizes all significant correlations between the modelled biometric parameters for the moderate $\mathrm{KC}$ group. Correlation coefficients between parameters for normal group have not been included, as their mutual relations have already been addressed in a previous study [16].

Table 4. The significant correlation coefficient values for the modelled variables in the moderate KC group.

\begin{tabular}{|c|c|c|}
\hline \multirow[b]{2}{*}{ Measurement correlation } & \multicolumn{2}{|c|}{ Moderate KC group $(n=43)$} \\
\hline & $\begin{array}{l}\text { Correlation } \\
\text { coefficient }\end{array}$ & $P$ value \\
\hline Splareapapex / Voltot & 0.965 & 0.000 \\
\hline Corareaant / Devpapex & 0.313 & 0.041 \\
\hline Corarea $_{\text {pos }} / \mathrm{Dev}_{\text {papex }}$ & 0.361 & 0.017 \\
\hline Corarea $_{\text {ant }} /$ Corarea $_{\text {pos }}$ & 0.941 & 0.000 \\
\hline Corarea $_{\text {ant }} /$ Corarea $_{\text {tot }}$ & 0.778 & 0.000 \\
\hline Corarea $_{\text {pos }} /$ Corarea $_{\text {tot }}$ & 0.864 & 0.000 \\
\hline Vol $_{\text {tot }} /$ Corarea tot & 0.354 & 0.020 \\
\hline $\mathrm{COM}_{\mathrm{x}} /$ Corarea $\mathrm{ant}$ & -0.340 & 0.025 \\
\hline $\mathrm{COM}_{\mathrm{X}} /$ Corarea $_{\mathrm{pos}}$ & -0.317 & 0.038 \\
\hline $\mathrm{COM}_{\mathrm{x}} /$ Corareatot $_{\mathrm{t}}$ & -0.361 & 0.017 \\
\hline
\end{tabular}




\begin{tabular}{|c|c|c|}
\hline $\mathrm{COM}_{\mathrm{x}} / \mathrm{COM}_{\mathrm{z}}$ & -0.369 & 0.015 \\
\hline $\mathrm{COM}_{\mathrm{z}}$ / Corareaant & 0.938 & 0.000 \\
\hline $\mathrm{COM}$ z / Corareapos & 0.882 & 0.000 \\
\hline $\mathrm{COMz} /$ Corareatot & 0.844 & 0.000 \\
\hline Devaminthk $_{\text {/ Dev }}$ papex & 0.440 & 0.003 \\
\hline $\operatorname{Dev}_{\text {pminthk }} / \operatorname{Dev}_{\text {papex }}$ & 0.532 & 0.000 \\
\hline $\operatorname{Dev}_{\text {aminthk }} / \operatorname{Dev}_{\text {pminthk }}$ & 0.979 & 0.000 \\
\hline Splarea $_{\text {minthk }} /$ Splarea $_{\text {papex }}$ & 0.997 & 0.000 \\
\hline Vol $_{\text {tot }} /$ Splarea $a_{\text {minthk }}$ & 0.963 & 0.000 \\
\hline $\operatorname{Dev}_{\text {aapex }} / \operatorname{Dev}_{\text {papex }}$ & 0.403 & 0.007 \\
\hline
\end{tabular}

\section{Discussion}

The cornea is a complex hemispheric structure, made of collagen fibres that provide it a homogenous and stable geometry. In a pathological scenario, a loss of tenacity takes place in the collagen fibres that form the corneal structure, producing an alteration of its geometry, this is, a change of its curvature, and therefore, a loss of visual quality of patients [22].

There are in scientific literature several works that have studied the geometry of corneas with a moderate degree of optical aberration [23,13,24]. Several studies [23] observed that corneal thickness is not constant in this pathology, as a thinning is produced in the region in which the loss of structural tenacity appears. These results are consistent with the ones obtained by other researchers [24] that analysed the thickness of corneas with an advanced degree of optical aberration. Other recent study has demonstrated that some morphological singularities as well as corneal thickness are related with disease progression [13]. Therefore, the cornea in this pathology shows a region of geometrical decompensation as a non-symmetric response to the disease progress. However, the parametrization and study of the correlation between the biometric parameters that register this decompensation, which allow to evaluate the progression of keratoconus with moderate visual loss, have not been analysed for each patient from a virtual model of their own eye.

In this study, all measures made have resulted consistent, and almost all mean differences have been statistically significant between healthy corneas and corneas with keratoconus showing a moderate degree of visual impair, except for the anterior/posterior minimum thickness point deviation. These results are in accordance with the ones reported by previous studies that evaluated some of these anatomic parameters with equipment based in Scheimpflug technology [25]. In our study, we have used a technology based in a double rotating camera based in the Scheimpflug projection system. This system has shown, in a previous study [26], being a robust and repeatable system for spatial data acquisition of the hemispheric structure, from which basing the generation of the virtual model with CAD software [17]. 
Regarding the AUROC, four parameters from all the ones analysed in our study showed very high discriminant values (AUROC $>0.9$ ). Two parameters, which are the anterior and posterior corneal surface areas showed AUROC values of 0.937 y 0.945 respectively, due to the fact that in the pathological scenario a biomechanical weakening takes place, caused by the loss of tenacity of the hemispheric structure and consequently, an increase of the corneal surface curvature is produced. This tendency is in line with some previous works that made ratio studies between anterior and posterior areas for different degrees of severity of the disease [25]. The other two parameters with high discrimination values were anterior apex deviation $($ AUROC $=0.910)$ and posterior apex deviation (AUROC $=0.945$ ), this is because the corneal apex is the point of maximum curvature in corneal surfaces, therefore, according with other authors [27], the apex deviation is a parameter that could affect the visual performance of the patients.

In this study, we have analysed the correlation between biometric parameters that register the structural alteration which manifests during the disease development. So, the parameters related with the areas show a strong positive correlation, specifically between anterior and posterior surface areas $\left(\mathrm{R}^{2}=0.941, \mathrm{p}=0.000\right)$, anterior surface area and total corneal surface area $\left(\mathrm{R}^{2}=0.778, \mathrm{p}=0.000\right)$ and posterior and total corneal surface areas $\left(R^{2}=0.864, p=0.000\right)$, due to the fact that corneal surfaces tend to behave proportionally during the evolution of the disease. These results are consistent with the ones obtained for corneal curvature in eyes with keratoconus, with the biomechanical weakening of the cornea, and with the possible effect of intraocular pressure in the weakened corneal structure [28].

Regarding anterior and posterior deviations, both between corneal apex points $\left(\mathrm{R}^{2}=\right.$ $0.832, p=0.000)$ and minimum thickness points $\left(R^{2}=0.997, p=0.000\right)$, there is a strong positive correlation, this is in line with the results reported by other authors [25] that demonstrated a robust correlation between apex deviation and the minimum thickness points and their relation with the pachymetric progression of corneal thickness.

\section{Conclusion}

The analysis of the biometric parameters that register the geometric decompensation that locally appear in a corneal region, as a response to the asymmetry produced during the development of keratoconus disease with a moderate degree of optical aberration, is a procedure that provides the ophthalmologist a new tool for the diagnosis of this pathology with this degree of development. In this work it has been ascertained that the most predictive biometric parameters are the anterior corneal surface area and the deviation of the posterior apex, detecting that the strongest correlation is the one between the areas of the sagittal planes defined through the minimum thickness points and the posterior corneal apex. The studied biometric parameters showed significant differences between groups. Therefore, this new approach based in the personalised diagnosis from a computational model may lead to a better understanding of the disease with this degree of optical limitation. 


\section{$6 \quad$ Funding}

Funding: This publication has been carried out in the framework of the Thematic Network for Co-Operative Research in Health (RETICS) reference number RD16/0008/0012 financed by the Carlos III Health Institute-General Subdirection of Networks and Cooperative Investigation Centres (R\&D\&I National Plan 2013-2016) and the European Regional Development Fund (FEDER).

\section{$7 \quad$ Additional Information}

Conflict of Interest: The authors have no conflict of interest to declare.

Financial Disclosure: Neither author has a financial or proprietary interest in any material or method mentioned.

\section{$8 \quad$ References}

1. Albertazzi R (2010) Queratocono: pautas para su diagnóstico y tratamiento. Buenos Aires: Ediciones Científicas Argentinas 6:123-135

2. Buey Salas M, Peris M (2014) Biomecánica y arquitectura corneal. Spain: ELSEVIER

3. Cavas-Martínez F, De la Cruz Sánchez E, Martínez JN, Cañavate FF, Fernández-Pacheco D (2016) Corneal topography in keratoconus: state of the art. Eye and vision 3 (1):5

4. Piñero DP, Alió JL, Alesón A, Vergara ME, Miranda M (2010) Corneal volume, pachymetry, and correlation of anterior and posterior corneal shape in subclinical and different stages of clinical keratoconus. Journal of Cataract \& Refractive Surgery 36 (5):814-825

5. Zadnik K, Barr JT, Edrington TB, Everett DF, Jameson M, McMahon TT, Shin JA, Sterling JL, Wagner H, Gordon MO (1998) Baseline findings in the Collaborative Longitudinal Evaluation of Keratoconus (CLEK) study. Investigative ophthalmology \& visual science 39 (13):2537-2546

6. McMahon TT, Szczotka-Flynn L, Barr JT, Anderson RJ, Slaughter ME, Lass JH, Iyengar SK, Group CS (2006) A new method for grading the severity of keratoconus: the Keratoconus Severity Score (KSS). Cornea 25 (7):794-800

7. Ukwatta E, Arevalo H, Rajchl M, White J, Pashakhanloo F, Prakosa A, Herzka DA, McVeigh E, Lardo AC, Trayanova NA, Vadakkumpadan F (2015) Image-based reconstruction of three-dimensional myocardial infarct geometry for patient-specific modeling of cardiac electrophysiology. Medical Physics 42 (8):4579-4590. doi:10.1118/1.4926428

8. Henckel J, Holme TJ, Radford W, Skinner JA, Hart AJ (2018) 3D-printed Patient-specific Guides for Hip Arthroplasty. Journal of the American Academy of Orthopaedic Surgeons 26 (16):e342-e348. doi:10.5435/JAAOS-D-16-00719

9. VanKoevering KK, Zopf DA, Hollister SJ (2019) Tissue Engineering and 3-Dimensional Modeling for Facial Reconstruction. Facial Plastic Surgery Clinics of North America 27 (1):151-161. doi:10.1016/j.fsc.2018.08.012

10. Liew YM, Khalid A, Tan LK, Lim E, Chan BT, Md Sari NAB, Chee KH, Abdul Aziz YF Spatial cardiac dysfunction assessment via personalized modelling from MRI. In: 2018 IEEE EMBS Conference on Biomedical Engineering and Sciences, IECBES 2018 - Proceedings, 2019. pp 69-74. doi:10.1109/IECBES.2018.8626668 
11. Naser MA, Sayed AM, Wahba AA, Eldosoky MAA Modeling Procedures for Breast Cancer Diagnosis based on Clinical Elastography Images. In: Proceedings - 2018 13th International Conference on Computer Engineering and Systems, ICCES 2018, 2019. pp 671-677. doi:10.1109/ICCES.2018.8639338

12. Cavas-Martínez F, Bataille L, Fernández-Pacheco DG, Cañavate FJF, Alio JL (2017) Keratoconus Detection Based on a New Corneal Volumetric Analysis. Scientific Reports 7 (1). doi:10.1038/s41598-017-16145-3

13. Cavas-Martínez F, Bataille L, Fernández-Pacheco DG, Cañavate FJF, Alió JL (2017) A new approach to keratoconus detection based on corneal morphogeometric analysis. PLoS ONE 12 (9). doi:10.1371/journal.pone.0184569

14. Cavas-Martínez F, Fernández-Pacheco DG, De La Cruz-Sánchez E, Nieto Martínez J, Fernández Cañavate FJ, Vega-Estrada A, Plaza-Puche AB, Alió JL (2014) Geometrical custom modeling of human cornea in vivo and its use for the diagnosis of corneal ectasia. PLoS ONE 9 (10). doi:10.1371/journal.pone.0110249

15. Alio JL, Pinero DP, Aleson A, Teus MA, Barraquer RI, Murta J, Maldonado MJ, Castro de Luna G, Gutierrez R, Villa C, Uceda-Montanes A (2011) Keratoconus-integrated characterization considering anterior corneal aberrations, internal astigmatism, and corneal biomechanics. J Cataract Refract Surg 37 (3):552-568. doi:10.1016/j.jcrs.2010.10.046

16. Cavas-Martínez F, Fernández-Pacheco DG, Cañavate FJF, Velázquez-Blázquez JS, Bolarín JM, Alió JL (2018) Study of morpho-geometric variables to improve the diagnosis in Keratoconus with mild visual limitation. Symmetry 10 (8). doi:10.3390/sym10080306

17. Cavas Martinez F, Garcia Fernandez-Pacheco D, Fernandez Cañavate FJ, Velázquez Blázquez JS, Bolarin JM, Tiveron M, Alio JL (2019) Detección De Queratocono Temprano Mediante Modelado 3D Personalizado Y Análisis De Sus Parámetros Geométricos. Dyna Ingenieria E Industria 94 (1):175-181. doi:10.6036/8895

18. Huseynli S, Salgado-Borges J, Alio JL (2018) Comparative evaluation of Scheimpflug tomography parameters between thin non-keratoconic, subclinical keratoconic, and mild keratoconic corneas. European Journal of Ophthalmology 28 (5):521-534. doi:10.1177/1120672118760146

19. Cavas-Martínez F, Fernández-Pacheco DG, Parras D, Cañavate FJF, Bataille L, Alió J (2018) Study and characterization of morphogeometric parameters to assist diagnosis of keratoconus. BioMedical Engineering Online 17. doi:10.1186/s12938-018-0564-7

20. Lasko TA, Bhagwat JG, Zou KH, Ohno-Machado L (2005) The use of receiver operating characteristic curves in biomedical informatics. Journal of Biomedical Informatics 38 (5):404-415. doi:https://doi.org/10.1016/j.jbi.2005.02.008

21. Pepe MS (2003) The statistical evaluation of medical tests for classification and prediction. Medicine,

22. Piñero DP (2015) Technologies for anatomical and geometric characterization of the corneal structure and anterior segment: a review. Semin Ophthalmol 30. doi:10.3109/08820538.2013.835844

23. Anderson K, El-Sheikh A, Newson T (2004) Application of structural analysis to the mechanical behaviour of the cornea. Journal of the Royal Society, Interface 1 (1):3-15. doi:10.1098/rsif.2004.0002

24. Gefen A, Shalom R, Elad D, Mandel Y (2009) Biomechanical analysis of the keratoconic cornea. Journal of the mechanical behavior of biomedical materials 2 (3):224-236. doi:10.1016/j.jmbbm.2008.07.002

25. Montalbán R, Alio JL, Javaloy J, Piñero DP (2013) Correlation of anterior and posterior corneal shape in keratoconus. Cornea 32. doi:10.1097/ICO.0b013e3182904950 
26. Cavas-Martínez F, Fernández-Pacheco DG, Cruz-Sánchez E, Nieto Martínez J, Fernández Cañavate FJ, Vega-Estrada A (2014) Geometrical custom modeling of human cornea in vivo and its use for the diagnosis of corneal ectasia. PLoS One 9. doi:10.1371/journal.pone. 0110249

27. Tomidokoro A, Oshika T, Amano S, Higaki S, Maeda N, Miyata K (2000) Changes in anterior and posterior corneal curvatures in keratoconus. Ophthalmology 107 (7):1328-1332

28. Piñero DP, Alió JL, Aleson A, Escaf Vergara M, Miranda M (2010) Corneal volume, pachymetry, and correlation of anterior and posterior corneal shape in subclinical and different stages of clinical keratoconus. J Cataract Refract Surg 36. doi:10.1016/j.jcrs.2009.11.012 